\title{
High pressure Marinelli for counting low activity compressedgas samples
}

Troy A Robinson, Nick R. Mann, Christopher P. Oertel, Matthew G. Watrous, Christopher A. McGrath, John P. Peterson

March 2017

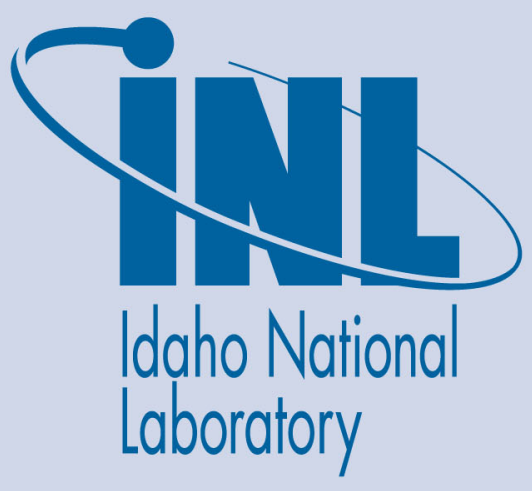

The INL is a U.S. Department of Energy National Laboratory operated by Battelle Energy Alliance 


\title{
High pressure Marinelli for counting low activity compressedgas samples
}

\author{
Troy A Robinson, Nick R. Mann, Christopher P. Oertel, Matthew G. Watrous,
} Christopher A. McGrath, John P. Peterson

March 2017

Idaho National Laboratory Idaho Falls, Idaho 83415

http://www.inl.gov

Prepared for the U.S. Department of Energy Office of Nuclear Energy Under DOE Idaho Operations Office

Contract DE-AC07-05ID14517 


\section{Title page}

2 Names of Authors: Troy A Robinson, Nick R. Mann, Christopher P. Oertel, Matthew G.

3 Watrous, Christopher A. McGrath, John P. Peterson

4 Title: High Pressure Marinelli for counting Low Activity Compressed Gas Samples

5 Affiliation(s) and Address(es) of the Author(s): Idaho National Laboratory Global

6 Security and International Safeguards Group: 2525 Fremont Ave, Idaho Falls, ID 83401,

7 USA. Idaho State University, ISU RISE Complex, 1999 Alvin Ricken Drive, Pocatello, 8 ID 83201, USA 


\section{High Pressure Marinelli for counting Low Activity}

\section{Compressed Gas Samples}

Troy A Robinson ${ }^{1}$, Nick R. Mann ${ }^{1}$, Christopher P. Oertel ${ }^{1}$, Matthew G. Watrous ${ }^{1}$,

$14{ }^{1}$ Idaho National Laboratory Global Security and International Safeguards Group: 2525 Fremont Ave, Idaho Falls, ID 83401, USA.

$$
\text { Christopher A. McGrath }{ }^{2} \text {, John P. Peterson }{ }^{1}
$$

\section{${ }^{2}$ Idaho State University, ISU RISE Complex, 1999 Alvin Ricken Drive, Pocatello, ID}

$$
\text { 83201, USA }
$$

19 Quantification of low-activity noble gases in air is typically accomplished through

20 separation of the noble gas from air followed by radiometric assay. This work is aimed at 21 quantification of radioactive noble gas in air without extraction. A high pressure 22 aluminum Marinelli counting vessel was designed and fabricated that can be placed on a

23 coaxial high purity germanium detector for gamma counting. Characterization of the 24 performance of this Marinelli using MCNP modeling, large excesses of activity, and low25 activity noble gas in air is discussed. Minimum detectable concentrations achieved during 26 a 24 hour count are: 5,50 , and $1 \mathrm{~Bq} / \mathrm{m}^{3}$ for ${ }^{133} \mathrm{Xe},{ }^{131 \mathrm{~m}} \mathrm{Xe}$, and ${ }^{135} \mathrm{Xe}$, respectively.

\section{Keywords}

28 High Pressure, Marinelli, Noble Gas, Gamma Counting, Radioactive Xenon 
30 The Comprehensive Test Ban Treaty (CTBT) prohibits nuclear tests above and below 31 ground, under water and in space [1]. This is to retard and discourage the development of 32 increasingly effective nuclear arms and to protect people and the environment from the 33 harmful effects of radioactive fallout [2]. Although the CTBT has not been ratified by all 34 members and is not yet in force, the Comprehensive Test Ban Treaty Organization 35 (CTBTO) is in the process of building and commissioning the International Monitoring 36 System (IMS). This monitoring system utilizes a variety of methods to look for illicit 37 nuclear detonations that include: seismic sensors [3], hydroacoustic microphones [3], 38 infrasound detectors [4], and radionuclide collection and analysis stations. By a 39 combination of these detection methods developing nuclear weapons through detonation 40 is difficult, if not impossible to do without being discovered.

41 The radionuclide collection and analysis stations screen samples for radionuclide 42 particulates [5] and radioactive xenon isotopes [6] that are characteristic of nuclear 43 detonations. Radiometric quantification of xenon radioisotopes in air is done routinely by 44 automated collection and separation systems [6-9]. These instruments must be calibrated 45 regularly in order to validate correct operation and ensure that results provide reliable 46 quantification. Inter-laboratory comparisons can verify that the stations are providing 47 equivalent results across the IMS.

48 The Idaho National Laboratory (INL) provides calibration standards specifically tailored

49 to testing the analytical capabilities of xenon detection equipment. Standards for testing 50 equipment that separates xenon from air are made by diluting quantitative amounts of 51 radioactive xenon into compressed whole air. During instrument development, xenon 52 radioisotope standards that do not require separation from air are desirable to test the 53 radioactive counting hardware without the complication of separation. Such standards are 54 made by diluting radioactive xenon into stable xenon[10].

55 During standards production it is desirable to non-destructively quantify the radioactive 56 xenon without the introduction of uncertainty caused by the separation from air. An 57 alternative to extraction of xenon is to analyze the whole air sample. Marinelli beakers 58 are typically used for counting large-volume, low-activity samples such as soils or water 
59 [11]. Marinelli beakers or "inverted well beakers" [12] consist of a large cylinder that has

60 an inverted well in the bottom that fits over the detector head of gamma detectors, often a

61 high purity germanium (HPGe) detector [11]. This shape minimizes the distance between

62 a detector head and a large volume sample under analysis. The current commercial option

63 for gas analysis by gamma counting is a Marinelli beaker with $1.4 \mathrm{~L}$ capacity and a

64 maximum pressure of 10 psig.

65 Current radioactive xenon in air standards produced by INL are certified by calculating 66 the final concentrations in air based on the activity of xenon radioisotopes and the total 67 mass of air added. Error propagation provides the uncertainty for the certified values. The

68 current process, however, does not provide a means of independently verifying the final 69 mixed standard, or the ability to detect problems that may occur during the transfer of 70 activity or mixing operation.

71 This work was undertaken to build a high pressure Marinelli that provides direct, non72 destructive quantification of a mixture of radioactive xenon in air standard. A secondary 73 goal of this work is to provide same-day qualitative confirmation that radioactive xenon 74 isotopes were successfully added to the standard before the packaged standard is shipped.

75 The aluminum Marinelli, whose design and testing is described in this article, provides a 76 direct, non-destructive analysis technique for the quantification of small concentrations of 77 xenon radioisotopes in air as a part of gas standard certification in the INL production 78 process.

\section{$79 \quad$ Experimental}

80 Monte-Carlo Modeling

81 Both the flat and round Marinelli geometries (see Fig. 1) were tested using the MCNP6 82 computer code. Each model calculation performed $5 \times 10^{7}$ particle histories and 83 determined the counting efficiency using the pulse-height tally. The source was modeled 84 as isotropic, monoenergetic $\left(81,163\right.$, and $249 \mathrm{keV}$ for ${ }^{133} \mathrm{Xe},{ }^{131 \mathrm{~m}} \mathrm{Xe}$, and ${ }^{135} \mathrm{Xe}$, each 85 modeled separately) photons that were emitted from random positions within the air 
86 sample cavity of the high pressure Marinelli. Calculations were performed on a desktop

$87 \quad$ PC and required approximately 6 minutes each.

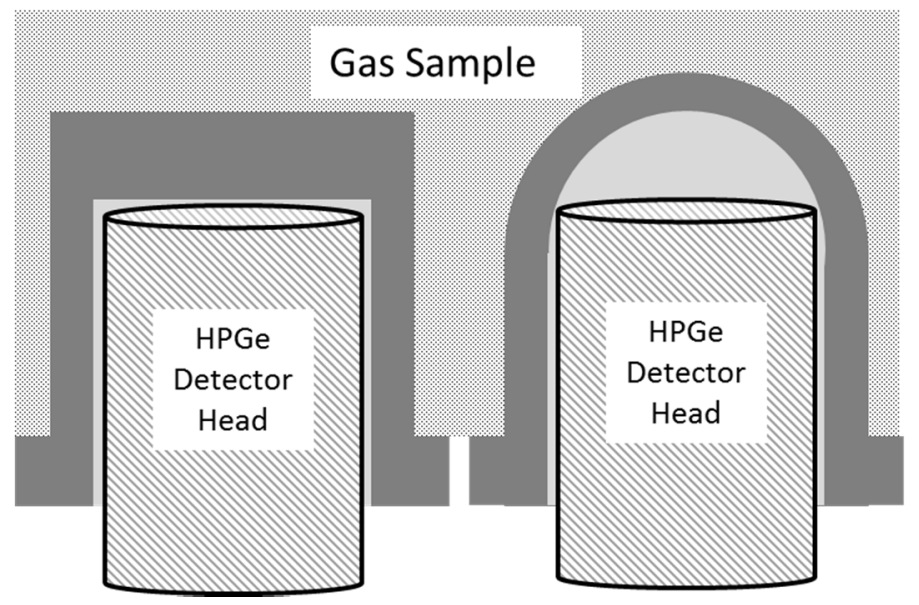

89 Fig. 1 Two alternative bottom Marinelli shapes: flat and round

90 Marinelli geometries were established from the fabrication design blue-prints. The

91 MCNP Marinelli design was simplified by eliminating the stainless steel outer shell

92 leaving an essentially bare sample air volume.

93 The HPGe detector geometry used in the model was approximated from the manufacturer

94 provided Quality Assurance Data sheet. From the data provided in the HPGe

95 documentation, it appears that the germanium crystal's physical dimensions were

96 measured in the factory, but the other dimensions involving the germanium's dead layer,

97 detector housing thickness and dimensions, and internal spacing were given as nominal

98 values. Verification of the dimensions on the detector's internal configuration could be

99 obtained by x-raying the detector head. This is not feasible due to the need to keep this

100 detector in service for the production of gas standards.

101 Radioactive Xenon Counting Experiments

102 The production and isolation of the ${ }^{131 \mathrm{~m}} \mathrm{Xe},{ }^{133} \mathrm{Xe}$ and ${ }^{135} \mathrm{Xe}$ are described in a previous 103 publication[10]. 
104 Air used in this study was obtained (Norco Gas, Inc.) as bottled whole compressed air.

105 The air was allowed to age for more than 90 days to ensure that any radioactive xenon

106 that may have been present in the gas at the time of bottling had decayed away. Un-

107 spiked samples of the air were loaded in the aluminum Marinellis and counted for more

108 than 80,000 seconds to obtain background spectra and to verify that no radioactive xenon

109 was present (MDC by isotope in $\mathrm{Bq} / \mathrm{m}^{3}:{ }^{131 \mathrm{~m}} \mathrm{Xe}=52 ;{ }^{133} \mathrm{Xe}=5 ;{ }^{133 \mathrm{~m}} \mathrm{Xe}=10 ;{ }^{135} \mathrm{Xe}=1$ ).

110 Xenon is typically moved via cryogenic transfer involving cooling either glass or metal

111 surfaces with liquid nitrogen and waiting for the xenon to freeze solid before sealing the

112 container holding the xenon. Because of the high pressures involved with the Marinelli, it

113 was not advisable to directly freeze the xenon in the Marinelli for fear of damaging the

114 vessel's structural integrity. An alternative method was developed where a stainless steel

115 length of tube bent in the shape of a $U$ (U-tube) was attached to the Marinelli prior to

116 loading with xenon. The xenon was then cryogenically transferred to the U-tube. After

117 the U-tube was sealed, it was connected to the Marinelli on one end, and a compressed

118 gas source on the other. Compressed air was then allowed to flush the xenon from the U-

119 tube into the aluminum Marinelli. Compressed air was added until the system until the

120 pressure reached $500 \mathrm{psig}$. Although the system is rated to $1000 \mathrm{psig}$, the operating

121 pressure of 500 psig was used to prevent the samples from being vented through the

122 pressure relief valve that was set to vent at 1000 psig. When the correct pressure was

123 reached, all of the valves were closed and the U-tube and Marinelli were disconnected

124 from the compressed air source and from each other.

125 Scoping experiments on the mass balance of introducing xenon samples into and 126 removing them out of the U-tube showed that approximately $3 \mu \mathrm{L}$ of xenon becomes 127 stuck in the U-tube. To decrease the total loss of activity, approximately $10 \mathrm{cc}$ of carrier 128 xenon was added to the radioactive xenon spike. This sample volume loss was used to 129 estimate the xenon residue independently of counting the U-tube. The estimated activity 130 loss was verified by direct radiometric assay of the U-tube to quantify the residual 131 radioactive xenon that remained in the U-tube during the transfer. Estimated and 132 observed radioactive xenon U-tube residues are shown in Table 1. Because the lost 133 radioactive xenon activities were more than two orders of magnitude below the 
134 uncertainty of the original spike material, the experimental activities were not corrected

135 to reflect the activity losses. The counting efficiency using the aluminum Marinelli with 136 an HPGe detector was determined by the ratio of the decay corrected counts obtained 137 from the aluminum Marinelli count to the initial activity of the radioactive xenon aliquot.

139 Table 1 Experimental data for feed ampoule activity, U-tube residual activity (estimated 140 and observed), and measured efficiency

\begin{tabular}{|c|c|c|c|c|c|}
\hline \multicolumn{2}{|c|}{$\begin{array}{c}\text { Experiment } \\
\text { Name }\end{array}$} & $\begin{array}{c}\text { Feed } \\
\text { Ampoule } \\
\text { Activity } \\
(\mathbf{B q})\end{array}$ & $\begin{array}{c}\text { Estimated } \\
\text { Residual } \\
\text { Activity } \\
(\mathbf{B q})\end{array}$ & $\begin{array}{c}\text { Observed } \\
\text { Residual } \\
\text { Activity } \\
(\mathbf{B q})\end{array}$ & $\begin{array}{c}\text { Counting } \\
\text { Conditions } \\
\text { MDA (Bq) }\end{array}$ \\
\hline \multirow{4}{*}{ Flat } & ${ }^{133} \mathrm{Xe}$ & $8,900 \pm 200$ & 2 & $4.1 \pm 0.3$ & 0.6 \\
\cline { 2 - 6 } & ${ }^{133 \mathrm{~m}} \mathrm{Xe}$ & $100 \pm 10$ & 0.03 & $<\mathrm{MDA}$ & 0.7 \\
\cline { 2 - 6 } & ${ }^{131 \mathrm{~m}} \mathrm{Xe}$ & $35,000 \pm 2,000$ & 9 & $11 \pm 1$ & 4 \\
\cline { 2 - 6 } & ${ }^{135} \mathrm{Xe}$ & $1,720 \pm 90$ & 0.4 & $0.72 \pm 0.04$ & 0.09 \\
\hline \multirow{4}{*}{ Round } & ${ }^{133 \mathrm{Xe}}$ & $8,900 \pm 200$ & 2 & $3.6 \pm 0.3$ & 0.9 \\
\cline { 2 - 6 } & $133 \mathrm{mXe}$ & $100 \pm 20$ & 0.03 & $<\mathrm{MDA}$ & 1 \\
\cline { 2 - 6 } & ${ }^{131 \mathrm{mXe}}$ & $35,000 \pm 2,000$ & 9 & $10 \pm 3$ & 7 \\
\cline { 2 - 6 } & $135 \mathrm{Xe}$ & $1,720 \pm 90$ & 0.4 & $0.55 \pm 0.05$ & 0.1 \\
\hline
\end{tabular}

142 Following the determination of counting efficiencies for both Marinelli types (round and

143 flat bottomed) for all three isotopes tested $\left({ }^{131 \mathrm{~m}, 133,135} \mathrm{Xe}\right)$ actual gas standards were 144 loaded into the Marinellis and counted. Pressure of the samples was 950 psig to 145 maximize the sample available for assay. Using a different pressure than was used to 146 determine counting efficiencies can introduce bias into the results. The magnitude of the 147 bias was explored using MCNP calculations. Modeling results showed that less than a $1 \%$ 148 performance loss between $500 \mathrm{psi}$ and $1000 \mathrm{psi}$ pressurized samples. Air sample size was 149 determined by the mass difference between the empty and loaded aluminum Marinelli. 150 Each determination consisted of 6 separate counts of the same aliquot of activity in the 
151 same Marinelli. The Marinellis were counted alternately and repositioned before each

152 count. To protect the HPGe detector from damage, the Marinelli, that weighs

153 approximately $22 \mathrm{~kg}$, was designed with a slight excess of diameter in the inner void, and

154 slightly more height than was necessary. After the Marinelli was placed over the detector,

155 the head of the HPGe detector was gently moved up into the Marinelli void until contact

156 occurred (the total distance was between 1-2 cm of vertical height adjustment). Each

157 count was stopped after the total counts in each region of interest was greater than $15840,000$.

159 Theory

160 Aluminum Marinelli Design Considerations

161 The design of the Aluminum Marinelli was dictated by constraints set by: 1) the size of 162 the HPGe detector head, 2) the space within the lead shielding enclosure, and 3) an 163 arbitrarily selected 1000 psig sample pressure. A Marinelli was designed to fit within 164 these constraints: large enough orifice to accept the detector head, outer shell small 165 enough to provide clearance for the flange bolts that hold the upper and lower pieces 166 together, walls thick enough to withstand 1000 psig. Two possible shapes were proposed 167 for the inner Marinelli wall (wall separating the air sample and the detector head: round 168 and flat (see Fig. 1). Based on structural strength, the round would provide a thinner wall, 169 but the sample would be slightly further away from the detector head (see Fig. 2). 170 Because the effect of the thinner wall and the larger distance from the detector, it was not 171 clear which design would provide the best performance, and thus both were built and 172 tested. 


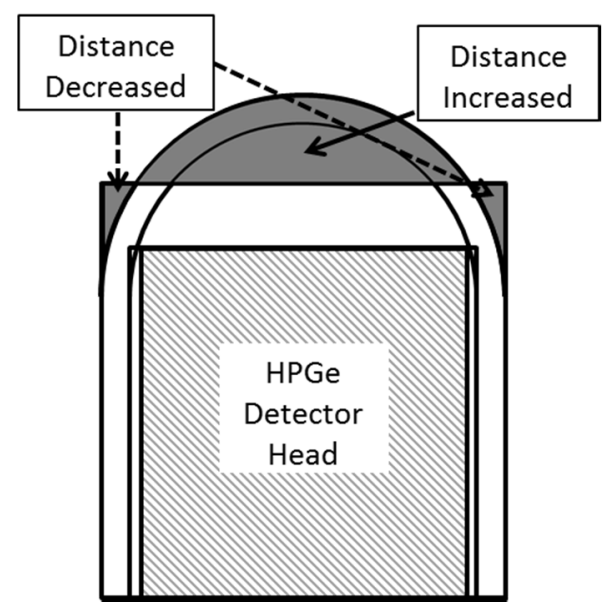

174 Fig. 2 An overlay of the round and flat bottom Marinellis showing the net distance 175 increase and decrease caused by switching from the flat to the round bottom Marinelli

176 Aluminum was chosen as the material for the lower wall due to its strength, 177 machinability, and lower attenuation than stainless steel. Beryllium has lower attenuation 178 than aluminum, but machining is problematic due to health concerns with beryllium dust. 179 Carbon also has a lower attenuation than aluminum, but manufacturing high pressure 180 carbon composite Marinelli was an expensive and complex task to be attempted only 181 after proof of concept was achieved.

\section{$182 \quad$ Results and discussion}

\section{MCNP Modeling Results}

184 The dimensions and material make-up of the Marinelli are rather simple to build into the 185 MCNP model. Detailed and precise blue-prints were converted into a three dimensional 186 replica of the Marinelli. The most challenging aspect of creating a virtual model that acts 187 the same as the aluminum Marinelli is obtaining an accurate description of the HPGe 188 detector head and housing. Ortec supplies a description of the layers, and thicknesses of

189 housing materials, germanium crystal dimensions, and dead-layer thickness, but these are 190 impossible to verify without irreversibly damaging the detector itself. 
191 The MCNP results show a general bias over the counting experiment results (see Table 2)

192 that range from 0.2 to $0.5 \%$ absolute efficiency ( 7 to $31 \%$ relative bias). We have 193 attempted various exercises to explain this difference in the results. One theory was that

194 the MCNP results are accurate, but the counting results suffered from losses due to

195 sample retention in the u-tube during the transfer to the Marinelli. U-tube residues were 196 counted using a calibrated counting geometry for the U-tube. The activity residues 197 observed account for less than $0.05 \%$ of the total activity necessary to account for the 198 total difference in the MCNP and counting experiment results.

199 Table 2 Comparison between MCNP modeling and Counting Experiment results

\begin{tabular}{|c|c|c|c|c|c|}
\hline \multirow[b]{2}{*}{ Isotope } & \multirow[b]{2}{*}{$\mathrm{E}_{\gamma}(\mathrm{keV})$} & \multicolumn{2}{|c|}{$\begin{array}{l}\text { MCNP Modeled Efficiency } \\
(\% \pm 1 \sigma)\end{array}$} & \multicolumn{2}{|c|}{$\begin{array}{c}\text { Counting Experiment Observed } \\
\text { Efficiency }(\% \pm 1 \sigma)\end{array}$} \\
\hline & & $\begin{array}{c}\text { Flat } \\
\text { Marinelli }\end{array}$ & $\begin{array}{c}\text { Round } \\
\text { Marinelli }\end{array}$ & $\begin{array}{c}\text { Flat } \\
\text { Marinelli }\end{array}$ & $\begin{array}{c}\text { Round } \\
\text { Marinelli }\end{array}$ \\
\hline${ }^{133} \mathrm{Xe}$ & 81 & $1.9 \% \pm 0.1 \%$ & $2.24 \% \pm 0.09 \%$ & $1.47 \% \pm 0.03 \%$ & $1.74 \% \pm 0.03 \%$ \\
\hline${ }^{131 \mathrm{~m}} \mathrm{Xe}$ & 163 & $2.94 \% \pm 0.08 \%$ & $3.28 \% \pm 0.08 \%$ & $2.5 \% \pm 0.1 \%$ & $2.9 \% \pm 0.1 \%$ \\
\hline${ }^{135} \mathrm{Xe}$ & 249 & $2.50 \% \pm 0.09 \%$ & $2.75 \% \pm 0.08 \%$ & $2.2 \% \pm 0.1 \%$ & $2.5 \% \pm 0.1 \%$ \\
\hline
\end{tabular}

201 Another possibility was that the HPGe dead layer estimated or calculated by Ortec was 202 inaccurate. This was a promising avenue of inquiry because early models for the 203 aluminum Marinelli that did not account for the HPGe dead layer showed efficiencies 204 that were 53\% higher than those modeled with the Ortec supplied dead layer thickness. A 205 set of calculations were undertaken to vary the thickness of the HPGe dead-layer to see 206 how much of a change would bring the MCNP results in line with the experimental 207 measurements. These calculations showed widely varying thicknesses depending on the 208 photon energy in question. The dead layers required to bring the results into line for ${ }^{133}$,

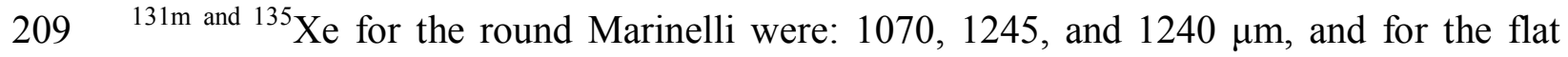
210 Marinelli were: 1123, 1438, and 1459, respectively. It would be plausible that the dead211 layer issue would be the source of the bias in the MCNP results if the dead-layer 212 thickness results all approached a single dead-layer value. The results however are 213 significantly different by isotope, and Marinelli shape, and thus this possible source of 214 MCNP results bias is rejected. It is possible to x-ray the detector head to verify the HPGe 
215 crystal dimensions and explore the possibility of undisclosed attenuating absorbers in the

216 detector head, but because this detector is in near constant use for gas standards

217 production, taking it out of service to $\mathrm{x}$-ray the head is not feasible.

218 Another possibility for the bias in the MCNP results relative to the counting results is an

219 incomplete elevation of the detector head. We reposition the detector head with each 220 count, so as to incorporate some of this random variability into the final efficiency. We 221 did undertake MCNP calculations to see how much of an effect forgetting to raise the 222 detector head would have on the observed count rates. The Marinelli internal shapes are 223 not equal, and thus one requires more lift than the other to put the detector into place. The 224 flat Marinelli requires $18 \mathrm{~mm}$ and the round Marinelli requires $13 \mathrm{~mm}$ of detector 225 elevation to be properly positioned. The MCNP results show that forgetting to raise the 226 detector in the flat and round Marinelli would decrease the count rate by $9.8 \%$ and $8.8 \%$, 227 respectively. Three assays of the round Marinelli where the detector was not raised and 228 we observed a negative bias in those counts of $12 \pm 4 \%$. This is the maximum effect that 229 would be observed due to detector elevation error. It is not likely that this maximum bias 230 exists in all the results, but there is probably a partial negative bias due to the random 231 effect of different operators raising the detector. The results in this paper are not 232 corrected for this bias due to the difficulty to measuring reliably the detector height, but it 233 is good to understand that some bias from this effect is probably present in the final 234 results.

235 Despite the bias in the MCNP results, they do show that the difference in performance 236 between the round and flat Marinelli shapes are consistent with the counting results. The 237 round Marinelli performs consistently better than the flat Marinelli at all gamma energies. 238 The relative trends in MCNP and counting results are very well captured, with ${ }^{131 \mathrm{~m} \mathrm{Xe}}$ 239 showing the highest counting efficiency. As discussed above, no single source of bias can 240 account for the differences between the two. Steps were taken to minimize the negative 241 bias effects in the counting experiments. It is most likely that some dimension of 242 attenuating materials in the detector head were not captured in the MCNP model, and 243 resulted in higher efficiencies that are achieved in the actual detector operation. The 
244 counting results are, however, a real indication of the expected operation of the detector

245 in the real world.

\section{Marinelli Counting Performance}

247 The Marinelli counting performance was carried out as described in the experimental 248 section. When the Marinellis were loaded with a sample, they hold $0.11 \pm 0.01 \mathrm{~m}^{3}$ of air 249 at 950 psig. The ${ }^{133} \mathrm{Xe}$ efficiency was lower than the ${ }^{131 \mathrm{~m}} \mathrm{Xe}$ and ${ }^{135} \mathrm{Xe}$ (Fig. 2) which can

250 be explained by the increased attenuation of gamma rays at lower gamma energies $\left({ }^{133} \mathrm{Xe}\right.$ $\left.251=81 \mathrm{keV} ;{ }^{131 \mathrm{~m}} \mathrm{Xe}=163.9 \mathrm{keV} ;{ }^{135} \mathrm{Xe}=249 \mathrm{keV}\right)$. There was a bias in the round bottomed 252 Marinelli over the flat bottomed Marinelli that was consistent across all gamma energies 253 of approximately $0.3-0.4 \%$ absolute efficiency (Table 2 ). In all cases the improved 254 performance of the round Marinelli was greater than the flat marinelli (approximately $25515 \%$ better relative performance).

256 Low-level Counting Performance

257 Following the performance testing of the Marinellis, they were filled with air that had 258 been spiked with radioactive xenon to see if the activity could be detected. The activity 259 concentrations of radioactive xenon in these air standards were $25.2 \mathrm{~Bq} / \mathrm{m}^{3}{ }^{135} \mathrm{Xe}$ and $2600.27 \mathrm{~Bq} / \mathrm{m}^{3}{ }^{133} \mathrm{Xe}\left(\mathrm{m}^{3}\right.$ at $0^{\circ} \mathrm{C}$ and $\left.1 \mathrm{~atm}\right)$. Within three hours of the beginning of the 261 count, a weak but distinct peak was observed in the $249 \mathrm{keV}$ energy region, confirming 262 the presence of ${ }^{135} \mathrm{Xe}$ in the standard. The counting was continued until the sample 263 activities had completely decayed. There were less than 1600 net total counts in the 249 $264 \mathrm{keV}$ peak and no counts above background were observed in the spectrum at $81 \mathrm{keV}$. 265 Because the ${ }^{135} \mathrm{Xe}$ had died before the count was stopped, no quantitative results could be 266 calculated. However, this experiment did show that a three hour count is sufficient length 267 to verify ${ }^{135} \mathrm{Xe}$ is present in an air sample prior to releasing the standard for shipping. It 268 may be possible to verify the presence of other isotopes if the air is spiked further in the 269 future.

270 This performance is in line with the expected minimum detectable concentrations 271 (MDCs) based on the detector background and measured efficiencies (see Table 3). 
272 These MDC values do not meet the CTBT Preparatory Commission's requirement of 1 $273 \mathrm{mBq} / \mathrm{m} 3{ }^{133} \mathrm{Xe}$ [14], nor near what is achieved by ARSA $\left(0.2 \mathrm{mBq} / \mathrm{m}^{3}\right.$ [14]), SPALAX $274\left(0.2 \mathrm{mBq} / \mathrm{m}^{3}[15]\right)$, or SAUNA $\left(0.6-0.9 \mathrm{mBq} / \mathrm{m}^{3}[8]\right)$. These systems take advantage of 275 the separation of the xenon fraction from bulk air (87 ppb Xe in air) to achieve much 276 greater sensitivity. It is notable that these systems theoretically benefit from a $10^{7}$ 277 preconcentration of the xenon analyte, they only achieve a $10^{5}$ improvement in 278 sensitivity. The Aluminum Marinelli was not intended to maximize sensitivity, but to 279 analyze an air standard without introducing uncertainty associated with xenon extraction.

280 Table 3 Minimum detectable concentrations achievable using the Aluminum Marinelli. 281 MDCs were calculated from the counting experiments efficiencies

\begin{tabular}{|c|c|c|c|c|c|}
\hline \multirow[b]{2}{*}{ Isotope } & \multirow[b]{2}{*}{$\mathrm{E}_{\gamma}(\mathrm{keV})$} & \multicolumn{2}{|c|}{$\begin{array}{l}\text { Quick Screening Count } \\
\text { (3 hour duration) } \\
\text { MDC }\left(\mathrm{Bq} / \mathrm{m}^{3}\right)\end{array}$} & \multicolumn{2}{|c|}{$\begin{array}{c}\text { Long Count } \\
(24 \text { hour duration }) \\
\text { MDC }\left(\mathrm{Bq} / \mathrm{m}^{3}\right) \\
\end{array}$} \\
\hline & & $\begin{array}{c}\text { Flat } \\
\text { Marinelli }\end{array}$ & $\begin{array}{c}\text { Round } \\
\text { Marinelli }\end{array}$ & $\begin{array}{c}\text { Flat } \\
\text { Marinelli }\end{array}$ & $\begin{array}{c}\text { Round } \\
\text { Marinelli }\end{array}$ \\
\hline${ }^{133} \mathrm{Xe}$ & 81 & 18 & 15 & 6.2 & 5.2 \\
\hline${ }^{13} \mathrm{~lm}^{\mathrm{m}} \mathrm{Xe}$ & 163 & 160 & 140 & 56 & 48 \\
\hline${ }^{135} \mathrm{Xe}$ & 249 & 4.1 & 3.6 & 1.4 & 1.3 \\
\hline
\end{tabular}

\section{Conclusions}

283 The fabrication of a working high pressure Marinelli for counting low activity gases has 284 been accomplished. Counting efficiencies and minimum detectable concentrations for ${ }^{133}$,

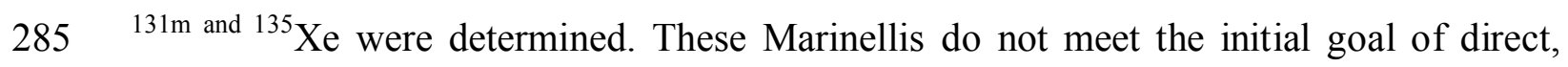
286 non-destructive quantification of the final mixed radioactive xenon in air standard. They 287 have shown to partially meet the goal of same day qualitative verification of successful 288 ioncorporation of the xenon radioisotope into the standard. Qualitative detection of ${ }^{135} \mathrm{Xe}$ 289 was accomplished when starting with a concentration of $25.2 \mathrm{~Bq} / \mathrm{m}^{3}$ of air. No detection 290 of ${ }^{133} \mathrm{Xe}$ at $0.27 \mathrm{~Bq} / \mathrm{m}^{3}$ of air was achieved in the same time frame. Improvements in 291 performance may be achieved by using lower attenuating material, such as carbon 292 composite materials. 
Journal of Radioanalytical and Nuclear Chemistry

\section{References}

294

295

296

297

298

299

300

301

302

303

304

305

306

307

308

309

310

311

312

313

314

315

316

317

318

319

320

321

322

1. Auer M, Kumberg T, Sartorius H, Wernsperger B, Schlosser C (2010) Ten years of development of equipment for measurement of atmospheric radioactive xenon for the verification of the CTBT. Pure Appl Geophys. 167:471-486

2. Comprehensive test ban treaty. Bureau of Arms Control, Verification and Compliance. http://www.state.gov/t/avc/trty/16411.htm. Accessed on 8/16/2016

3. Bondar I, North RG (1999) Development of calibration techniques for the comprehensive nuclear-test-ban treaty (CTBT) international monitoring system. Phys Earth Planet Inter. 113:11-24

4. Christie DR, Vivas Veloso JA, Campus P, Bell M, Hoffman T, Langlois A, Martysevich P, Demirovic E, Carvalho J (2001) Detection of atmospheric nuclear explosions: the infrasound component of the international monitoring system. Kerntechnik. 66:96-101

5. Werzi R (2009) The operational status of the IMS radionuclide particulate network. J Radioanal Nucl Chem. 282:749-754

6. Bowyer TW, Schlosser C, Abel KH, Auer M, Hayes JC, Heimbigner TR, McIntyre JI, Panisko ME, Reeder PL, Satorius H, Schulze J, Weiss W (2002) Detection and analysis of xenon isotopes for the comprehensive nuclear-test-ban treaty international monitoring system. J Environ Radioact. 59:139-151

7. Dubasov YV, Popov YS, Prelovskii VV, Donets AY, Kazarinov NM, Mishurinskii VV, Popov VY, Rykov YM, Skirda NV (2005) The AРИКС-01 automatic facility for measuring concentrations of radioactive xenon isotopes in the atmosphere. Instrum Exp Tech. 48:373-379

8. Ringbom A, Larson T, Axelsson A, Elmgren K, Johansson C (2003) SAUNA-a system for automatic sampling, processing, and analysis of radioactive xenon. Nucl Instrum Methods Phys Res Sec A. 508:542-553

9. Fontaine JP, Pointurier F, Blanchard X, Taffary T (2004) Atmospheric xenon radioactive isotope monitoring. J Environ Radioact. 72:129-135

10. Watrous MG, Delmore JE, Hague RK, Houghton TP, Jenson DD, Mann NR (2015) Radioxenon Spiked Air. J Environ Radioact. 150:126-131 
323 11. Debertin K, Jianping R (1989) Measurement of the activity of radioactive samples in 324 Marinelli beakers. Nucl Instr Methods Phys Res A. 278:541-549

325 12. Lavi N, Alfassi ZB, Drndarski N (1997) Calibration of Marinelli vessels for 326 measurement of radioactive environmental samples. Nucl Instr Methods Phys Res A. $327 \quad 385: 376-380$

328 13. Lemmon EW (2015) Thermophysical Properites of Air. CRC Handbook of Chemistry 329 and Physics 95th Ed. Internet Version

330 14. McIntyre JI, Abel KH, Bowyer TW, Hayes JC, Heimbigner TR, Panisko ME, Reeder 331 PL, Thompson RC (2001) Measurements of ambient radioxenon levels using the 332 automated radioxenon sampler/analyser (ARSA). J. Radioanal Nucl Chem. 248:629_ $333 \quad 635$

334 15. Topin S, Greau C, Deliere L, Hovesepian A, Taffary T, Le Petit G, Douysset G, 335 Moulin C (2015) SPALAX new Generation: New process design for a more efficient 336 xenon production system for the CTBT noble gas network. J Environ Radioact. $337 \quad 149: 43-50$ 